\title{
How to translate scientific knowledge into practice? Concepts, models and application
}

\author{
Como traduzir o conhecimento científico à prática? Conceitos, modelos e aplicação \\ ¿Cómo traducir el conocimiento científico a la práctica? Conceptos, modelos y aplicación
}

'Universidade Federal de Pelotas. Pelotas, Rio Grande do Sul, Brazil. "University of Toronto. Toronto, Canada. I'University of Ottawa. Ottawa, Canada.

\author{
Ana Cláudia Garcia Vieira' \\ ORCID: 0000-0001-8393-4711 \\ Denise Gastaldo" \\ ORCID: 0000-0003-3001-7981 \\ Denise Harrison"' \\ ORCID: 0000-0001-7549-7742
}

How to cite this article:

Vieira ACG, Gastaldo D, Harrison D. How to translate scientific knowledge into practice? Concepts, models and application. Rev Bras Enferm. 2020;73(5):e20190179. doi: http://dx.doi.org/10.1590/0034-7167-2019-0179

Corresponding author:

Ana Cláudia Garcia Vieira E-mail: cadicha10@gmail.com

EDITOR IN CHIEF: Dulce Aparecida Barbosa ASSOCIATE EDITOR: Antonio José de Almeida Filho

Submission: 09-18-2019

Approval: 10-06-2019 ABSTRACT
Objectives: to present the concept of Knowledge Translation and Exchange as it has been
used in the international literature and in Canada, particularly. Next, to describe a renowned
conceptual model to guide its implementation, entitled Knowledge-to-Action Cycle. Results:
we described the use of the model in the context of the municipal primary health care system
in southern Brazil for the implementation of pain management strategies during vaccination.
Conclusions: in this theoretical reflection, we argue that in order to promote health equity
and quality of care in the Unified Health System (Brazilian SUS) it is important to translate
scientific knowledge to various practice settings and create opportunities for exchange with
users of this knowledge, such as health professionals, managers, policy makers, patients,
family members and other stakeholders.
Descriptors: Knowledge Translation; Translation; Information Dissemination; Diffusion; Clinical competence.

\section{RESUMO}

Objetivos: apresentar o conceito de Tradução e Intercâmbio do Conhecimento tal como vem sendo utilizado na literatura internacional e, em particular, no Canadá. A seguir, descrever um renomado modelo conceitual para orientar a sua implementação, intitulado Ciclo do Conhecimento à Ação. Resultados: ilustramos a utilização do modelo no contexto do sistema municipal de atenção básica à saúde no sul do Brasil, na implementação de estratégias de manejo da dor durante a vacinação. Conclusões: nesta reflexão teórica, argumentamos sobre a importância de se traduzir o conhecimento científico aos diversos contextos de prática e criar oportunidades de intercâmbio com os usuários desse saber, como profissionais de saúde, gestores, formuladores de políticas públicas, pacientes, familiares e demais grupos de interesse, para promover equidade e qualidade dos cuidados no Sistema Único de Saúde. Descritores: Tradução do Conhecimento; Translação; Disseminação de Informação; Difusão; Competência Clínica.

\section{RESUMEN}

Objetivos: presentar el concepto de Traducción e Intercambio de Conocimiento tal como se ha utilizado en la literatura internacional y, en particular, en Canadá. A continuación, describir un modelo conceptual reconocido para guiar su implementación, titulado Ciclo del Conocimiento a la Acción. Resultados: ilustramos el uso del modelo en el contexto del sistema municipal de atención primaria de salud en el sur de Brasil para implementar estrategias de manejo del dolor durante la vacunación. Conclusiones: en esta reflexión teórica, argumentamos sobre la importancia de traducir el conocimiento científico a los diversos contextos de práctica y de crear oportunidades de intercambio con los usuarios de este conocimiento, como profesionales sanitarios, gerentes, formuladores de políticas públicas, pacientes, familias y otros grupos de interés para promover la equidad y la calidad de los cuidados en el Sistema Único de Salud.

Descriptores: Traducción del Conocimiento; Traducción; Diseminación de Información; Difusión; Competencia Clínica. 


\section{INTRODUCTION}

Internationally, health systems address the constant challenge of improving the quality of care and reducing the risk of inadequate or insufficient treatment while remaining economically viable. Ideally, in this process, beyond responding to the growing demand for health services of different levels of complexity, interventions effectiveness, cost-benefit ratio and user satisfaction should be evaluated ${ }^{(1)}$.

In this article, we describe the efforts made to bring academic outputs closer to those who should benefit from this knowledge, overcoming the "ivory tower" model, in order to facilitate an understanding of international trends in this area in Canada and Brazil. In Canada, where two of the authors are academics, the Canadian Institutes for Health Research (CIHR), the federal funding agency for health research established in 2000, was fundamental in the promotion of the concept of Knowledge Translation and Exchange (KTE) for professional practice and public policies.

Due to the investment of almost two decades, there has been a readjustment in research projects and study funding formulas, which should be aligned with the needs of users or stakeholders, defined as patients, family members and caregivers, professionals, managers and policy makers, in search for greater quality of care and less health inequities. This process has been criticized because it overvalues applied knowledge and devalues new concepts and ideas that cannot be used immediately. However, it undoubtedly mobilized researchers to consider knowledge translation and/or exchange with users as phases of research projects.

In Brazil, there is interest in producing knowledge that improves the quality of services offered by the Unified Health System (Brazilian SUS) and promotes the social relevance of publicly funded research conducted at federal and state universities. Therefore, the aim of this article is to introduce the concept of knowledge translation and exchange, present a well-established, specific conceptual model called the "Knowledge-to-Action Cycle"(1-2) and illustrate its use in a clinical setting in the municipal primary health care system in southern Brazil.

\section{KNOWLEDGE TRANSLATION AND EXCHANGE}

In Portuguese, the word translation refers to the process in which the native of a language can communicate in another language. In English, this meaning was used in the concept of Knowledge Translation and Exchange (KTE) given the understanding that scientific language is not commonly accessible to users and professionals of the health system. Thus, a translation is needed for scientific knowledge to be utilized.

Academics are traditionally inclined to transfer or disseminate knowledge, which often means publishing and presenting study results in conferences. The concept proposed by the Canadian Institutes of Health Research ${ }^{(1)}$ offers a much more ambitious proposal by stating that the KTE process requires concrete changes hence, it is defined as:

"A dynamic and iterative process that includes the synthesis, dissemination, exchange and ethically sound application of knowledge to improve health, provide more effective health services and products and strengthen the healthcare system"(1).
In the international literature, there are many terms used to describe this approach, but in Canada, KTE is the most frequently used term in health sciences because it is adopted by the country's main scientific funding organization. Yet, in England and the USA, the terms knowledge exchange, research use and implementation are commonly used. This variety of nomenclature has caused confusion, as researchers often use the terms separate from their conceptual and theoretical models. There is also a tendency to use different terminology in different countries depending on the approaches adopted by their respective research funding agencies ${ }^{(3)}$.

Chart 1 - English and Portuguese nomenclature of models for scientific knowledge translation to health practice

\begin{tabular}{|c|c|c|c|}
\hline \multicolumn{2}{|r|}{ English } & \multicolumn{2}{|l|}{ Portuguese } \\
\hline \multirow{3}{*}{ 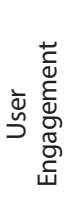 } & Knowledge Diffusion & Difusão do conhecimento & \multirow{3}{*}{ 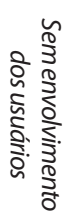 } \\
\hline & $\begin{array}{l}\text { Knowledge transfer/ } \\
\text { dissemination }\end{array}$ & $\begin{array}{c}\text { Transferência/disseminação } \\
\text { do conhecimento }\end{array}$ & \\
\hline & $\begin{array}{c}\text { Research utilization/ } \\
\text { use }\end{array}$ & $\begin{array}{l}\text { Uso/utilização } \\
\text { da pesquisa }\end{array}$ & \\
\hline \multirow{3}{*}{ 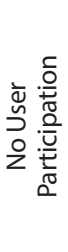 } & $\begin{array}{l}\text { Knowledge transfer } \\
\text { and uptake }\end{array}$ & $\begin{array}{l}\text { Transferência e adoção } \\
\text { do conhecimento }\end{array}$ & \multirow{3}{*}{ 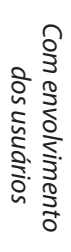 } \\
\hline & Knowledge translation & $\begin{array}{l}\text { Tradução ou translação } \\
\text { do conhecimento }\end{array}$ & \\
\hline & $\begin{array}{l}\text { Knowledge translation } \\
\text { and exchange }\end{array}$ & $\begin{array}{l}\text { Tradução e intercâmbio do } \\
\text { conhecimento }\end{array}$ & \\
\hline
\end{tabular}

Using the term KTE presupposes considering many forms of knowledge in order to change practices or policies, including research data, local context data, organizational priorities, organizational culture, patients' experience and preferences, and the availability of resources ${ }^{(1)}$. Knowledge translation strategies vary according to audience targeting (for example, researchers, clinicians, or policy makers) and the type of knowledge to be translated ${ }^{(1)}$.

The purpose of KTE is to spread the benefits of knowledge produced to as many people and institutions as possible by assessing the impact of these interventions from the perspective of health promotion and harm reduction as well as replacement or elimination of provenly inefficient and costly therapeutic practices. Therefore, KTE means promoting access to knowledge and enjoying the benefits of excellence in health care, from a democratic and equitable perspective, so that all health system users receive the best care at the lowest possible risk. In addition, since most research is publicly funded, researchers should give back to society the investment made in their studies. When KTE becomes a study phase or an integrated research strategy, the study may last longer, but the KTE will be funded as a component of the study.

Regarding clinical practice, studies unfortunately point to a significant number of health care professionals who are not yet confident about their ability to critically assess the evidence available in systematic reviews, feeling unprepared for interpreting the assumptions of evidence-based practice ${ }^{(4-5)}$.There are also difficulties in accessing databases and other sources, such as the guidance from qualified professionals, associated with the lack of tradition in collaborative work with researchers. 
Even participatory and action research methodologies, which are traditional in Latin America, are still seldom used in health services. When used, they are centered on the production of new contextualized knowledge and commonly do not synthesize and integrate prior knowledge.

Regarding the activities involved in the KTE process, two categories describe how and when it is performed: a) Translation of knowledge at the end of a research project, which includes the development and implementation of a plan in which potential users are provided with knowledge about project results (translation) and activities that engage groups to exchange ideas on the implementation of study results in different local contexts (exchange); b) Integrated knowledge translation, which is a participatory approach to engage knowledge users throughout the research process. This leads to users' greater understanding and interest in using research results in their decision making process ${ }^{(6)}$.

The effectiveness of KTE, whether integrated or at the end of a study, varies widely ${ }^{(7)}$. These are projects of great complexity. In our experience, factors that could not be anticipated can create tensions and even make projects unfeasible, such as unusual power relations that characterize some professional groups or different objectives between researchers and stakeholders for the same project. Often, researchers' lack of preparedness to manage networks and groups (existing and new ones) for conducting processes with transparency and working simultaneously with managers, users and professionals (understanding hierarchies, but not reproducing paternalistic or discriminatory relationships) becomes the main barrier to the project success ${ }^{(7)}$. In the Brazilian and Ibero-American context, where there is limited use of KTE, capacity building for researchers and financial support for projects with a KTE phase would be the first twosteps to foster the development of this bridge approach between science and society.

Given this reality, in order to translate knowledge into clinical practice, researchers should adopt a model to guide the process which is understood by frontline health care workers. Multiple models can be chosen to guide KTE, for example, "Promoting Action on Research Implementation in Health Services" (PARIHS), Public Involvement Impact Assessment, CIHR Model of Knowledge Translation, or The Ottawa Model of Research Use. Among the options available, a frequently used conceptual model, currently adopted by the World Health Organization, is the "Knowledgeto-Action Cycle"(1-2), described below.

\section{KNOWLEDGE-TO-ACTION CYCLE MODEL}

The conceptual model called the Knowledge-to-Action Cycle was developed by Graham and colleagues in $2006^{(2)}$ from the review and aggregation of over 60 theories, frameworks, and action planning models. The approach proposed in this model was expanded in later publications, as illustrated in Figure 2, and guided studies by Canadian researchers ${ }^{(8)}$.

This diagram supports the understanding of researchers and knowledge end-users because it is accessible, as a map of phases to be followed in the KTE process, to address a specific issue, in a particular direction, in a concrete context ${ }^{(9)}$. End-users (stakeholders) must be included throughout the process to ensure KTE relevance by considering their needs ${ }^{(1)}$.
The current diagram ${ }^{(1)}$ comprises two distinct but related components: (a) Knowledge Creation, with the central figure of a funnel (the old model was an inverted triangle) subdivided into three phases: knowledge inquiry (first generation of knowledge: primary studies),knowledge synthesis(second generation knowledge: systematic literature review) and knowledge tools/ products(third generation knowledge: decision-support protocols, clinical guidelines or educational modules); (b) Action cycle, which has seven interrelated steps that influence each other. Each component involves several overlapping phases that can be iterative, and the knowledge phases can impact the action phases ${ }^{(9)}$.

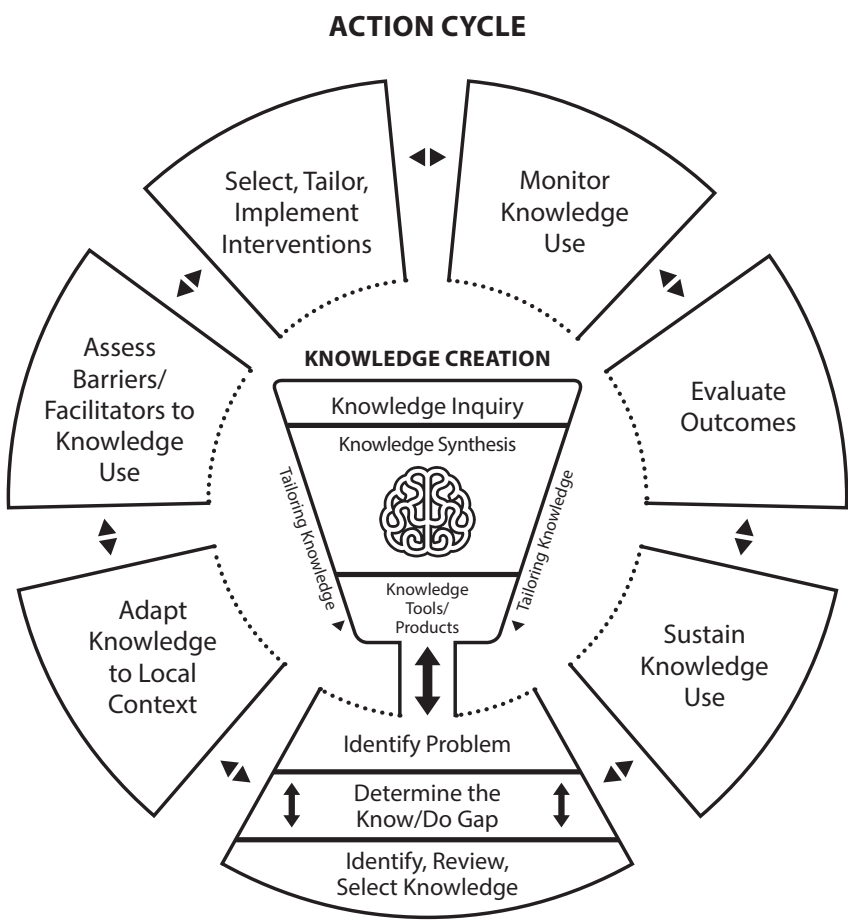

Source: Straus, Tetroe \& Graham, 2013; Graham et al, 2006 (translated and validated by Ana Claudia Vieira and Denise Gastaldo with permission of the authors and publisher John Wiley\&Sons).

Figure 1 - Knowledge-to-Action Cycle

While researchers generally work more intensively on product discovery, synthesis and design, stakeholders have great influence on the bottom of the funnel, which includes problem identification and gaps between knowing and doing and the review and selection of knowledge that will be used.

The edges of the cycle diameter show the six core steps of KTE after considering the problem, knowledge and reality. They are: adaptation of knowledge to the local context, assessment of barriers and facilitators for knowledge use, selection and tailoring for implementation of interventions, monitor knowledge use, evaluation of outcome and sustain knowledge use. This whole process follows a nonlinear course, as each step is closely related to the others and allows fluid movement between them, i.e., researchers and interest groups can use the steps out of sequence depending on the project.

The Action Cycle describes the approach process of planned and necessary actions for the practical application of knowledge. The starting point involves a group or an individual who identifies a 
problem that deserves consideration. After the identification of its relevance, the problem should be critically evaluated to determine if it is a priority and of interest for all involved, which can be done in group meetings by reviewing and determining the knowledge gap.

The next step is the adaption of knowledge to the local context, when the particularities, values, potential acceptance and adequacy of this knowledge to the circumstances of a specific context are examined. This step involves assessing barriers and facilitators, supporting potential targeted interventions in order to deal with resistance and/or promote the next step, which involves selecting and designing activities with the aim to promote awareness and knowledge implementation. In this step, innovative strategies should be used, moving away from the traditional ones, such as article publication (passive diffusion), to include materials aimed at the audience and context (e.g. videos, reminders, interactive educational sessions, scientific cafés and social media).

Thereafter, the focus of subsequent steps is the monitoring, evaluation and use of knowledge to assess the impact of the application on the health of individuals and/or the system. In other words, if there has been change and if it was successful compared to the situation prior to the KTE project.

Finally, in the step of sustaining the knowledge use, Graham et al. ${ }^{(2)}$ suggest a similar process to the initial step of assessing barriers and facilitators, but with a different approach aimed at assessing the factors that prevent or promote the maintenance of knowledge application. They mention that, in order to achieve sustainability, a dynamic feedback system should be created, connecting all steps of the action cycle ${ }^{(2)}$.

This model was designed so that the various stakeholders who collaborate with researchers can work systematically, favouring the understanding of each step, so that they make sense in the real world given the idiosyncrasies related to the various contexts. As a conceptual model, it is easily adaptable to different health care practice settings, whether in primary healthcare, hospital care or other situations, such as guiding the introduction of evidence-based practice into nursing undergraduate education.

\section{USE IN THE CLINICAL SETTING: APPLICATION OF THE MODEL}

Our example is an integrated KTE project for pain management in newborns and infants during immunizations, a study conducted by two of the authors of this article (ACV and DH), that has been developed in partnership with the Health Department of Pelotas (RS), since January 2018. The research project was approved by the Research Ethics Committee of the Faculty of Medicine, Universidade Federal de Pelotas (protocol 2.437.042). The project was conceived during the postdoctoral program of one of the authors (ACV) at the University of Ottawa, given the lack of a similar project in the Brazilian context.

In this approach, the priority was to build a professional relationship based on trust and respect with the collaboration of all involved. A working group was formed in each community health centre with engagement of nurses and technicians (local leaders) in a flexible process, considering the context of stakeholders ${ }^{(1)}$.

In order to illustrate its use in the clinical setting, the steps of the conceptual model Knowledge-to-Action Cycle are described with examples of actions developed either simultaneously, alternately or sequentially.

Problem identification: identification of the absence or insufficient management of pain caused by immunizations in children from 0 to 12 months when there are feasible, efficient and inexpensive interventions described in the scientific literature, such as breastfeeding, skin-to-skin contact and use of sweetened solutions.

Determining the gaps: initially, the knowledge of nurses and technicians about pain management practices during painful procedures was assessed using a questionnaire (pilot study). Parents shared their opinions on the feasibility of the procedures after watching videos demonstrating pain reduction interventions.

Selecting knowledge: in this step, updated systematic reviews that responded to the identified problem were selected. A synthesis of knowledge is not always available for the problems identified. Sometimes, it is necessary to perform a literature review (scope review, integrated review or systematic review). In our case though, there were recent systematic reviews and new guidelines on pain mitigation recommendations prepared by the WHO expert group in September 2015 (http://www.who. int/immunization/sage/en). This knowledge was the basis for the creation of working groups in three community health centres.

Adaptation of knowledge to the local context: through a partnership with managers from the Municipal Health Department, members of the health care team were observed while working in the vaccination room and the resources available for the adoption of recommendations were assessed (e.g. physical space, chairs for the correct positioning of parents, availability of sweetened solutions, and receptivity of stakeholders). The work process performed during this step of the model had the participation of managers, health professionals and parents' representatives.

Assessment of barriers and facilitators: the main barriers found were the lack of knowledge about guidelines and protocols, fear of implementing the recommended measures due to concern for children's safety and lack of availability of sweetened solutions (sucrose and glucose). As an example of facilitating factors, we identified the team's openness to learn and managers'support. The meetings took place as scheduled by the team members of each community health centre. In these meetings, the lead researcher shared the content of the WHO and HELPinKIDS guidelines ${ }^{(10)}$ during discussion groups, when myths and concerns regarding pain management strategies were addressed.

Selecting, tailoring and implementing interventions: the WHO pain mitigation document published in English and French was translated into Brazilian Portuguese by one of the authors under supervision of a native English reviewer, which allowed access to information. In addition, videos produced by one of the authors (DH) were used (https://www.youtube.com/watch?v=2TyTPDghiXE) with audio in Portuguese (translated by ACV), describing pain management interventions in a clear, accessible language, informing parents, nurses and nursing technicians how to proceed during vaccination. Additionally, flowcharts were used describing in detail how to use the interventions, with pictures and clear text, in a user-friendly and attractive style.

Monitoring knowledge use: the direct observation of the practices adopted and feedback from stakeholders (parents, nurses and technicians) has revealed satisfaction with the process so far. 
Evaluation of outcome: until now, parents reported satisfaction and confidence to vaccinate their children in the three community health centres. There was an increased demand from mothers, who showed interest in the use of breastfeeding for pain reduction. The evaluation of outcomes will be developed subsequently to assess the satisfaction of parents and health care professionals who adopted the strategies.

Sustain knowledge use: based on discussion groups and questionnaire data collected, a booklet was developed (Module I) for nurses and technicians. Next, we will produce educational tools for parents. Following, we will organize activities, such as "Scientific Cafes" with participation of the local community, researchers and managers in order to reach a wide audience.

At the federal level, one of the authors (ACV) collaborated with the review of the Immunization Standards and Procedures Manual under the coordination of the National Immunization Program of the Ministry of Health, with the aim of incorporating these guidelines into vaccination procedures across the country in the medium term.

\section{FINAL CONSIDERATIONS}

In the Brazilian context, the possibility of translating evidence into clinical practice and establishing exchanges with stakeholders in their various settings is a challenge, but also a possibility of increasing nursing autonomy and visibility as well as of other health professional groups. In part, the success of these projects depends on the use of conceptual KTE models that better fit the context of each project.

The Canadian experience reveals several elements involved in the power relations among researchers, stakeholders and the organizational context, which may facilitate or defy the process, consequently, affecting the success of the implementation.

Furthermore, recognizing the incipient level of partnership among researchers, professionals, patients, families and institutions in Brazil is paramount, as well as the scarcity of public funding and low investment in research of this nature. It is also necessary to train researchers and students to develop critical skills for assessing the quality of scientific publications to consider whether they should be applied to health care settings.

In summary, the common goal of KTE guided by diverse conceptual models is to understand, from the perspective of knowledge users, what is effective and promotes health equity for the population, while it positively impacts on the excellence and sustainability of the health care system.

\section{FUNDING/ACKNOWLEDGEMENT}

Coordination for the Improvement of Higher Education Personnel (CAPES): Processes: 99999.007463/2015-04. Program: 227. Posdoctoral Research Abroad. To Dr. lan Graham, to the managers, nurses and technicians at the Basic Health Units of the Pelotas Health Department (Bom Jesus, Simões Lopes and Puericultura), Amanda Riboriski and Valentina Gastaldo.

\section{REFERENCES}

1. Straus SE, Tetroe J, Graham ID. Knowledge Translation in Health Care: moving from evidence to practice. 2nd ed. Wiley Blackwell; $2015406 \mathrm{p}$.

2. Graham ID, Logan J, Harrison MB, Straus SE, Tetroe J, Caswell W, et al. Lost in knowledge translation: time for a map? J Contin Ed Health Prof. 2006; 26(1):13-24. doi: 10.1002/chp.47

3. Mckibbon KA, Lokker C, Wilczynski NL, Ciliska D, Dobbins M, Davis DA, et al. A cross sectional study of the number and frequency of terms used to refer to knowledge translation in a body of health literature in 2006: a Tower of Babel? Imp Sci. 2010; 5(16): 1-11. doi: 10.1186/1748-5908-5-16

4. Squires JE, Estabrooks CA, Scott SD, Cummings GG, Hayduk L, Kang SH, et al. The influence of organizational context on the use of research by nurses in Canadian pediatric hospitals. BMC Health Serv Res [Internet]. 2013 [cited 2017 May 21];13(351):1. Available from: https:// bmchealthservres.biomedcentral.com/articles/10.1186/1472-6963-13-351

5. Sackett DL, Rosenberg WM, Gray J, Haynes RB, Richardson WS. Evidence Based Medicine: What it is and what it isn't. BMJ [Internet]. 1996 [cited 2018 Apr 14];312(7023):71-2. Available from: http://www.bmj.com/cgi/content/full/312/7023/71.

6. Gagliardi AR, Berta W, Kothari A, Boyko J, Urquhart R. Integrated knowledge translation (IKT) in health care: a scoping review. Imp Sci. 2016;11(38):1-12. doi: 10.1186/s13012-016-0399-1

7. Greenhalgh T. What is this knowledge that we seek to "exchange"? Milbank Q. 2010;88(4):492-9. doi: 10.1111/j.1468-0009.2010. 00610.x

8. Lang ES, Johnson D. How does "knowledge translation" affect my clinical practice? Can J Emerg Med. 2012;14(3):182-6. doi: $10.2310 / 8000.2012 .110645$

9. Field B, Booth A, llott I, Gerrish K. Using the Knowledge to Action Framework in practice: a citation analysis and systematic review. Imp Sci. 2014; 9(172):1-14. doi: 10.1186/s13012-014-0172-2

10. Taddio A, McMurtry CM, Shah V, Riddell RP, Chambers CT, Noel M, et al. Reducing pain during vaccine injections: Clinical practice guideline. Cmaj [Internet]. 2015 Sep [cited 2018 Jul 06];187(13):975-82. Available from: http://www.cmaj.ca/content/cmaj/187/13/975.full.pdf 